\title{
PPI in the PLEASANT trial: involving children with asthma and their parents in designing an intervention for a randomised controlled trial based within primary care
}

\author{
Jonathan Boote ${ }^{1}$, Steven Julious ${ }^{2}$, Michelle Horspool ${ }^{3}$, Heather Elphick ${ }^{4}$, W. Henry Smithson ${ }^{5}$ and \\ Paul Norman ${ }^{6}$, On behalf of the PLEASANT study team \\ ${ }^{1}$ Reader in Patient Experience and Public Involvement, Centre for Research in Primary and Community Care, \\ University of Hertfordshire, Hertfordshire, UK \\ ${ }^{2}$ Professor of Medical Statistics, Medical Statistics Group, School of Health and Related Research, University of \\ Sheffield, Sheffield, UK \\ ${ }^{3}$ Research Fellow, Clinical Trials Research Unit, School of Health and Related Research, University of Sheffield, \\ Sheffield, UK \\ ${ }^{4}$ Consultant in Paediatric Respiratory Medicine, Sheffield Children's NHS Foundation Trust, Sheffield, UK \\ ${ }^{5}$ Professor of General Practice, Department of General Practice, University College Cork, Cork, Ireland \\ ${ }^{6}$ Professor of Health Psychology, Department of Psychology, University of Sheffield, Sheffield, UK
}

\begin{abstract}
Aims: We describe how patient and public involvement (PPI) was integrated into the design of an intervention for a randomised controlled trial (RCT) based within primary care. The RCT, known as the PLEASANT trial, aimed to reduce unscheduled medical contacts in children with asthma associated with start of the new school year in September with a simple postal intervention, highlighting the importance of maintaining asthma medication for helping to prevent increased asthma exacerbations. Background: PPI is a key feature of UK health research policy, and is often a requirement of funding from the National Institute for Health Research. There are few detailed accounts of PPI in the design and conduct of clinical trials in the PPI literature for researchers to learn from. Methods: We held PPI consultation events to determine whether the proposed intervention for the trial was acceptable to children with asthma and their parents, and to ascertain whether enhancements should be made. Two PPI consultation events were held with children with asthma and their parents, prior to the research commencing. Detailed field notes were taken by the research team at each consultation event. Findings: At the first consultation event, parents and children endorsed the trial's rationale, made suggestions to the wording of the trial intervention letter, and made recommendations about to whom the letter should be sent out. At the second consultation event, parents discussed the timing of the intervention, commented on the lay summary of the Research Ethics Application, and were invited to join the trial's steering committee, while the children selected a logo for the study. PPI has resulted in enhancements to the PLEASANT study's intervention. A further PPI consultation event is scheduled for the end of the trial, in order for children with asthma and their parents to contribute to the trial's dissemination strategy.
\end{abstract}

Key words: asthma; clinical trial design; patient and public involvement; primary care

Received 29 June 2015; revised 21 December 2015; accepted 10 January 2016;

first published online 9 February 2016

Correspondence to: Dr Jonathan Boote, Reader in Patient Experience and Public Involvement, Centre for Research in Primary and Community Care, University of Hertfordshire, College Lane, Hatfield, AL10 9AB, UK. Email: j.boote@herts.ac.uk 


\section{Introduction}

In recent years, patient and public involvement (PPI) has become established as a key component of health research policy both in the UK and internationally (National Health \& Medical Research Council and Consumers' Health Forum of Australia, 2002; Department of Health, 2005; Canadian Institutes of Health Research, 2010; Patient Protection and Affordable Care Act, 2010). In the UK, the National Institute for Health Research (NIHR) is committed to active PPI, where appropriate, in all research studies that it funds, and has stated that PPI: 'is an essential part of the development of modern health and social care services. Research that reflects the needs and views of the public is more likely to produce results that can be used to improve health and social care' (National Institute for Health Research, 2015).

PPI in research is defined as research undertaken with, or by, patients and the public, rather than research which is on, for, or about them (INVOLVE, 2015). A contrast is drawn between active involvement and participation in research; those who are actively involved are not participants - they are advisors or co-researchers. In addition to being a policy imperative, PPI in research is underpinned by epistemological, moral and consequentialist arguments, which state that: health research benefits from involving people with the lived experience of the disease, illness or condition; patients and the public have a moral right to be actively involved in any research which may impact on their health or the services that they receive; and research that actively involves patients and the public is likely to be of higher quality, greater clinical relevance, and more likely to be implemented (Boote et al., 2015a).

Benefits of PPI, as reported in recent systematic reviews of the evidence base, include: identification of more patient-centred research topics; improved feasibility of study design; more effective recruitment strategies; more patient-centred data analysis; improved dissemination; and improving researchers' links to the wider community (Staley, 2009; Brett et al., 2010; Shippee et al., 2013). While the PPI literature has expanded considerably in recent years (Boote et al., 2015a), there have been repeated calls for its impact to be demonstrated more systematically (Staniszewska et al., 2008; Barber et al., 2011).
Due to its high status within evidence hierarchies, one of the most important types of health research in which to involve patients and the public is the clinical trial (Boote et al., 2011), and their roles in prioritising trials (Partridge and Scadding, 2004; Couzos et al., 2005), ensuring the ethical acceptability of trial design (Staniszewska et al., 2008; Brett et al., 2010), drafting trial information leaflets (Hanley et al., 2001) and promoting trials to potential participants (Consumers in NHS Research, 2000) have all been identified. Recent surveys of clinical trials, carried out by the Medical Research Council and the NIHR Stroke Research Network, found $31 \%$ and $54 \%$ of trials, respectively, had PPI either in study design or conduct (Vale et al., 2012; Boote et al., 2015b). However, as identified in a narrative review of the field (Boote et al., 2011), the literature describing PPI within individual clinical trials is relatively small at present, with few detailed examples for researchers to draw on. Since this review was published, a small number of further examples of PPI in clinical trials have appeared in the literature (Edwards et al., 2011; Littlewood et al., 2013, Koniotou et al., 2015).

Researchers undertaking clinical trials where the end beneficiaries are children should find ways to actively involve children in the research process wherever possible. There is a growing body of literature detailing the practice of actively involving children and young people in the design and conduct of health research; the benefits and challenges children's active involvement brings to research; and its practical and ethical implications (Morrow and Richards, 1996; Thomas and O'Kane, 1998; Alderson, 2001; Kirby, 2004; Kellett, 2005; 2009; McCarry, 2005; McLaughlin, 2005; 2006; 2007; Brownlie et al., 2006; Gorin et al., 2008; Uprichard, 2010; Oliver et al., 2015). McCarry (2012) talks of a paradigm shift having occurred whereby social scientists no longer need to justify why children and young people should be actively involved in research; rather, the focus is now on how best it can be achieved. In the UK, this paradigm shift can be seen in the extensive guidance offered by INVOLVE and the National Children's Bureau for how researchers can best involve children and young people in research (National Children's Bureau, 2010; INVOLVE, 2015), along with the establishment of a number of young people's advisory groups, such as the

Primary Health Care Research \& Development 2016; 17: 536-548 
National Young People's Mental Health Advisory Group (INVOLVE, 2015).

This paper describes the involvement of children with asthma and their parents (taken to include parents or guardians throughout this paper), over the course of two consultation events, in the design of a trial intervention to reduce unscheduled medical contacts in children with asthma after the start of the new school year. We critically reflect on the approach we took to actively involve children and parents in the design of the trial, drawing on Fleming and Hudson's (2009) model of involving young people in research, and we discuss the lessons that we have learned.

\section{The PLEASANT trial: background and summary of overall design}

Within the UK, during September, there is a pronounced increase in the number of unscheduled medical contacts by school-aged children (4-16 years) with asthma (Julious et al., 2007). It is hypothesised that this increase in medical contacts is caused by the return back to school after the summer holidays, with children with asthma suddenly mixing with other children again and picking up viruses which could impact adversely on their asthma. In addition, this peak in contacts is preceded by a drop in the number of prescriptions administered in August, with children not getting prescriptions in August more likely to see their doctor in September (Julious et al., 2011).

The 'Preventing and Lessening Exacerbations of Asthma in School-age children Associated with a New Term' (PLEASANT) trial was designed to investigate whether a simple intervention of a letter from the general practitioner (GP) to parents of children with asthma at the start of the summer holiday period, highlighting the importance of maintaining asthma medication, could help prevent increased asthma exacerbations, and unscheduled NHS appointments, following return to school in September.

PLEASANT was a cluster randomised trial which recruited 142 general practices across England and Wales: 70 intervention and 72 control practices to 'usual care'. An average practice was expected to have approximately 100 children (aged 4-16 with a diagnosis of asthma); hence observational data were collected on around
14000 children. The Clinical Practice Research Datalink (CPRD) (Williams et al., 2012) was used to collect the data required for the study. Further details about the PLEASANT trial can be found in the published protocol (Horspool et al., 2013).

\section{Method of PPI engagement in the trial design}

While the grant application for the PLEASANT trial was being prepared for submission to NIHR Health Technology Assessment (HTA), funding was obtained from the NIHR Research Design Service Yorkshire and Humber to hold a consultation event with children with asthma and their parents. Due to a tight submission deadline, a convenience sample of children with asthma and their parents was identified locally by two clinical members of the research team (HE and WHS), from among the children with asthma known to them through their clinical work at the Sheffield Children's Hospital's respiratory clinic and in general practice. Children with asthma and their parents identified via the respiratory clinic were approached to participate by asthma nurses, while those identified via general practice were invited to attend by letter. These methods of recruitment were chosen in an effort to minimise any possible coercion: the research team thought potential participants would be more comfortable saying 'no' to the asthma nurse rather than the doctor (who was also a member of the research team) if they did not wish to take part, while the invitation letter used to recruit via general practice gave participants the chance to think about whether or not they wished to take part.

The first consultation event was held at the Sheffield Children's Hospital in the early evening and light refreshments were provided. Expenses for attendees' travel were provided. In addition, the children were given a small $£ 20$ gift voucher in recognition of their time, which was the maximum amount that could be provided to members of the public participating in consultation events run by University of Sheffield staff. A voucher was provided rather than cash, as a cash payment would have meant obtaining each parent's (or child's) bank account details, setting up each on the University payroll system and then paying each retrospectively. A voucher payment meant that payment for time could be made on the actual day of the consultation 
event, and also meant that the voucher could be given to each child in attendance. The first consultation event was designed to obtain views about the rationale for the PLEASANT trial, and the acceptability and wording of a draft of the intervention (the letter from a general practitioner). The team also wanted to obtain views from attendees about whether the letter should be addressed to the child or to the parent. All attendees agreed to be contacted for future consultation events should the grant be successfully awarded.

Following confirmation of funding from the HTA, a second consultation event was held at the University of Sheffield with children with asthma and their parents while the protocol was being finalised. The same children with asthma and their parents who participated in the first consultation event were invited to the second event.

The purpose of the second event was to inform attendees that the grant was successful, to provide feedback on how their suggestions were incorporated into the study protocol, and to finalise the content of the intervention letter and its scheduled timing in relation to the end of the summer term and the start of the new school year. Comments were also invited on the draft of the lay summary of the submission to the Research Ethics Committee, and the children were invited to give their input into the design of a logo for the study. As with the first consultation event, the second event was held in the early evening, attendees were reimbursed for their time and travel, and light refreshments were provided.

Guided by advice from INVOLVE and the National Research Ethics Service, we did not seek informed consent from the children and parents attending the two consultation events, nor were the events audio-recorded (INVOLVE and the National Research Ethics Service, 2009). Instead, members of the research team observed both events and took detailed field notes of the discussions that took place.

\section{Results}

\section{Consultation one: pre-grant submission (January 2011)}

The first consultation event was attended by five children with asthma (aged between 7 and 14) and their parents. Four of the five children were girls, and all the children were Caucasian. The event began with a welcome and a short presentation about the study by the chief investigator (S.J.). Children and parents were then invited to participate in separate facilitated discussions in different rooms. The children's discussion group was facilitated by a paediatric respiratory consultant (HE), while the parents' discussion was facilitated by an academic GP (WHS). Both facilitators were members of the research team.

\section{Discussion with children}

The children were initially invited to respond to general questions about their asthma, in an attempt to get them to feel comfortable talking in front of other (in some cases older) children. In a further effort to put the children at their ease, the preliminary questions were put in sealed envelopes, and each child was invited to pick one at random and then read it out to the rest of the group.

As part of the preliminary discussion, the children were asked to talk about what impact their asthma has on their life, and how it affects them at school and at home. The children mentioned the activities they enjoyed and how asthma impacted on them. The facilitator then moved the conversation on to the research study, by asking the children to think about which parts of the year their asthma is particularly bad. Most agreed that they tend to be unwell after the return to school in September because they pick up bugs from the other children, although some mentioned that August could also be a bad month, due to undertaking strenuous exercise during the summer holidays, higher pollen counts, and going on holidays abroad to hot countries.

The children were then introduced to the idea behind the research study, and were shown a copy of the intended letter from the GP (see Figure 1). All the children were supportive of the study. The children were asked if the letter should be addressed to the child with asthma, or to their parent, or if separate letters should be addressed to the parent and the child in the same envelope. The children agreed that the letter should be addressed to their parent, and not the child, even if the child was as old as 16 . The children did not see any particular value in including a separate letter for the child. The children were asked to consider if the letter should be personalised, or if it could just say 'Dear parent'. Most children felt 
$<$ Practice Address line $1>$
$<$ Practice Address line $2>$
$<$ Practice Address line $3>$
$<$ Practice Address line $4>$
$<$ Insert Date $>$
Dear Parent
Asthma can get worse when the summer holidays end resulting in a number of
children and young people with asthma getting poorly around this time of year.

This may be due to exposure to infections at the start of the new school year.

To keep well at this time of year, we would encourage you to make sure your child takes their asthma sprays as prescribed by your GP or practice nurse. If your child has stopped taking inhalers over the summer holidays please make sure they restart them at least 2 weeks before returning to school. If your inhalers are in short supply (or you are unsure as to which inhalers your child should be taking), please get in touch with the practice.

Yours sincerely

$<$ Name of Doctor $>$

Figure 1 Initial draft of GP letter shown at the first consultation event

it did not matter whether the letter was personalised because parents will have a reason to read the letter - as the letter is clearly in their child's interest.

\section{Discussion with parents}

The discussion opened with the facilitator presenting the rationale behind the proposed trial that the study was designed to address the problem of the seasonal exacerbations in childhood asthma, which seem to be triggered by the return of children back to school - and the possible reasons which may underpin this phenomenon. The parents were largely supportive of the trial's rationale and understood the theories outlined by the facilitator, with one parent mentioning that her daughter was hospitalised due to her asthma in the immediate weeks after the return to school in September. At this stage of the discussion, the parents considered a range of triggers of their child's asthma, including pollen and seasonal allergens, exercise and infections such as cold viruses, and discussed other times in the year when their child's asthma is also problematic.

Primary Health Care Research \& Development 2016; 17: 536-548
The facilitator then moved the discussion onto the proposed intervention for the trial - the letter from the GP-and asked the parents if they thought such a letter would be suitable for all parents of children with asthma, or if it would be ignored or considered intrusive by parents who did not think the start of the school year is an issue for triggering an exacerbation in their child's asthma. The facilitator read the letter out to the parents, asking if they thought it is written in the right language, and would be understandable to most parents. The facilitator asked the parents to consider a range of options regarding to whom the letter should be addressed-should it:

- Be addressed to the parent only

- Be addressed to the child only

- Be jointly addressed to the parent and child

- Consist of separate letters to the parent and child, with letters sent in a jointly addressed envelope.

All the parents considered that the letter would be more likely to be welcomed as a helpful reminder than be seen as intrusive. One parent said it would definitely be helpful for her because 
she leaves some of her daughter's inhalers at school during the holidays. The letter was likened to other useful reminders sent out by different organisations such as the Driver and Vehicle Licensing Agency or the TV licensing office. One parent said that because parents do not necessarily take inhalers themselves, the reminder letter serves a useful purpose as parents often forget to ask their children if they are taking their inhalers. One parent thought that the letter could be strengthened by saying that the parent should be stocking up on inhalers now and making sure that the child is taking them, which could reduce problems/exacerbations in the run-up to wintertime. There was general agreement that the letter gave sufficient information and there was a discussion about whether or not the letter should be addressed to the parent and to the child. There was concern that if the letter was just addressed to the child who is a reluctant user of an inhaler, then the parent might not see the letter. So, the parents suggested that a compromise might be for a joint letter to be sent out, or a letter addressed to the child and a letter addressed to the parent in the same envelope.

\section{Consultation 2: post-award, pre-commencement (September 2012)}

Attendees at the second consultation event consisted of three parents and four children with asthma (two of whom were siblings). Three of the children were girls. Two of the children were Caucasian and two were of Asian ethnicity. The children were aged 11 years and under. Some attendees of the first event unfortunately could not attend the second event, so the team's clinical members invited some different parents and children to the second event, using the same recruitment methods as for the first consultation. The second event was facilitated by the chief investigator (S.J.), and began with a presentation on the current status of the work, and developments since the first event. The parents and children were then invited to comment on the latest draft of the GP letter (the study intervention), the timing of when the letter should be sent out, and the lay summary of the ethics application. The children were then invited to select a logo for the study, from three that had been prepared by the trial manager (M.H.).

There was much discussion about the latest draft of the letter, which the research team had decided, for practical and financial reasons, was going to be addressed solely to the parent. The general feeling among the group was that the letter did not adequately reflect the seriousness of asthma as a health condition. It was felt therefore that there was a danger that the letter could be ignored by parents, or that the information it contained could be forgotten about. Therefore, the group agreed on new wording that appeared in bold at the start of the letter (see Figure 2), which stressed that the content of the letter is important and that it has the potential to impact directly on the health of their child with asthma.

The group discussed whether the letter could be sent to the parent more than once. Although this was seen as a good idea in principle, as it would reinforce the message, the research team explained that it would not be possible because of the study design: the research team would not be able to tell if it was the first or the reminder letter that had the main effect.

One parent enquired about whether the intervention will be translated for parents for whom English is not their first language. It was explained that funding had been secured for translation services, and that the letter would be able to be translated into different languages if required.

The timing of the intervention was also discussed. One parent stated that the letter should perhaps not be sent out too early in July because, at that point, the start of the new school year seems so far off. After further discussion, it was agreed that the letter would be posted the week commencing 29 July 2013 - which was at the start of the six-week summer school holiday.

The group was then asked to comment on the lay summary of the application that the research team will shortly be making to the Research Ethics Committee. The group thought that the summary was understandable and gave a clear summary account of the aims and methods of the study. No major changes were suggested by the group to the wording of the summary, although it was agreed that certain words be removed in order to improve its clarity (see Figure 3 ).

The children considered three possible logos for the study, which would feature on the study website, future publications and study publicity material. The children agreed that the logo for the trial should feature a girl and a boy, with the name of the study featured inside a drawing of an inhaler

Primary Health Care Research \& Development 2016; 17: 536-548 
GP letterhead

$<$ Address line $1>$

$<$ Address line 2>

$<$ Address line $3>$

$<$ Address line 4>

$<$ Insert Date>

Dear Parent

\section{Please read this important letter regarding your child's asthma}

It is really important that your child continues to take their asthma medication during the summer holidays. Returning to school is a time when asthma can get worse and make children and young people with asthma poorly. This may be due to contact with infections at the start of the new school year.

To reduce the chances of getting poorly when they return to school, your child should continue to take their asthma medication as prescribed by their GP or practice nurse. If your child has stopped taking their medication over the summer holidays it is important to start it again as soon as possible. If they are short of medication, or you are not sure of the proper dose, please get in touch with the practice.

Yours sincerely

$<$ Name of Doctor $>$

Figure 2 The revised intervention letter, changed following patient and public involvement (PPI) input

In the UK there is a pronounced increase in the number of visits to the doctor by school age children with asthma in September. It is thought that that this might be caused by the return to school, when children with asthma will be mixing with many other children again and picking up bugs which can affect their asthma and make them poorly.

During the summer holidays there is a drop in the number of prescriptions collected. August is a good month to be an asthmatic - children with asthma are not mixing with many other children and the pollen count is quite low - therefore children with asthma might not take their medication as they should or allow their medication to run low.

We hope that a simple letter from the GP, reminding children with asthma to take their medication or to collect their prescriptions, can help prevent them being poorly in September. The letter itself will say that returning to school can increase the chance of a child with asthma being poorly. It will suggest that parents ensure their children's medication is fully up to date and they take their medication daily if they need to for at least 2 weeks before going back to school.

To see if the letter works we will ask some GPs to send it out to the parents of school aged children with asthma, and some GPs will not, so that we can compare whether the letter has had any effect. We will be looking at a number of factors including whether children who get the letter see their GP less in September. In addition to the number of visits made to their doctor we will be looking at the number of prescriptions children with asthma have and the effect on costs to the NHS.

Figure 3 Final content of the study's lay summary of the Research Ethics Committee application, following patient and public involvement (PPI) input

Primary Health Care Research \& Development 2016; 17: 536-548 


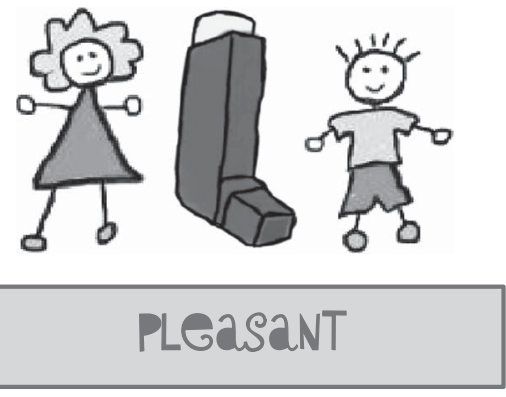

Figure 4 Final study logo, co-designed with children with asthma involved in the study

if possible, or that the inhaler should be placed between the boy and girl (see Figure 4).

The group was then shown the current study website, and the list of all the researchers who are involved in the study. It was agreed that there should be a link on the website to information about the involvement of children with asthma and their parents in the study. All the parents and children present agreed for their names to appear on this new webpage (and the parents signed an agreement for this), and the research team agreed to contact the parents and children once this new webpage has been uploaded onto the internet The PPI pages for the PLEASANT trial can be viewed at: https:/www.shef.ac.uk/scharr/sections/dts/ctru/ pleasant/ppi (last accessed, 21 December 2015).

The research team finally explained to the group that the trial will be overseen by a Trial Steering Committee (TSC), which makes sure that the study runs at it should. It was stressed that, as well as GPs, asthma experts and statisticians, it is also important that two parents of children with asthma are also members of this Committee. Those parents present at the second consultation were invited to attend the first meeting of the TSC. (Parents present at the first consultation event were also approached to see if they would be willing to join the TSC). Three parents agreed to be contacted to participate in the TSC meetings. Of these parents, two subsequently joined the TSC.

\section{Discussion}

Throughout the two consultation events, the parents and children found the proposed trial to be of value, with parents stating that they would welcome the intervention letter as a useful reminder in preparing for their child's return to school in September. In keeping with the literature on PPI in trial development (Boote et al., 2011), the parents consulted offered useful suggestions for improving the PLEASANT trial's intervention, in particular with regard to the wording of the letter, and its timing in relation to the start of the summer holidays. The children consulted provided useful reassurance to the research team that it would be acceptable for the letter to be addressed to the parent rather than the child with asthma. It was interesting that both the parent's and children's focus group thought that the intervention letter should be addressed to the parent rather than to the child, or to both. If there had been disagreement about this, the research team had planned to extend the consultation event to hold a short plenary discussion to try to reach a consensus among the whole group.

Great care was taken during the consultation process to involve children as well as their parents in the design of the PLEASANT trial's intervention. Previous authors have highlighted the important contributions that children can make to research when they are actively involved in the process, as either co-researchers (Alderson, 2001; Kellett, 2005; McLaughlin, 2005; 2006; 2007; Brownlie et al., 2006) or as advisors to a research team (Clavering and McLaughlin, 2010; Oliver et al., 2015). The present paper contributes particularly to the PPI literature on the involvement of children as advisors to a research team, and complements a recent account of how children were consulted on the process of conducting two systematic reviews on the topic of obesity (Oliver et al., 2015).

We used a variety of methods and techniques to maximise the way that children could advise the research team on the development of the PLEASANT trial, and to put them at ease during the process, including: inviting them to participate in separate discussions to their parents; easing them into the research topic area by asking more general questions at the start of the discussion; and putting questions into sealed envelopes, and asking each child to pick an envelope and to read the question out - this latter technique acted both as an ice-breaker, and as a way of adding a sense of fun to the proceedings. The team also sought to enhance children's involvement in the study by asking them to choose a study logo, by placing 
their names on the study website, and each received a certificate of attendance.

With respect to the 'extent' or 'type' of children's involvement in the PLEASANT trial, it is useful to reflect on this using Fleming and Hudson's (2009) model of involving young people in research. In this model, Fleming and Hudson combine the approach of Hanley et al. (2003) (who classified PPI into consultation, collaboration or user-led), with Hart's (1992) conceptualisation of tokenism, in order to suggest four approaches to involving young people in research. A tokenistic approach to involvement is where there is no real attempt to involve young people in a way that would give them some influence over the research. Consultation is the practice of asking for the views and perceptions of young people during the design and/or conduct of the research, and where this feedback is used to improve aspects of the research. Collaboration is a partnership between the researcher or practitioner and the young people. In this collaborative approach, the research often remains researcher led, but a twoway relationship is fostered in which the young people play an equal role and are often actively involved at all stages of the research process. Finally, in young people-controlled research, the young people themselves are fully engaged in and in control of the research, which only involves professionals or adult researchers if they are invited by the young people. With respect to the involvement of the children within the PLEASANT trial, they were involved in discussions about aspects of the trial's intervention at the design stage, such as to whom the intervention letter was addressed to, but they were not involved in the actual conduct of the research - children were not members of the trial's steering committee for example, nor was a children's reference group established to inform the conduct of the trial. A children's reference group was considered when PPI for the study was being planned, but the research team could not see a meaningful role that children could play during the conduct of the research, due to the technical nature of the trial itself: the observational nature of the trial meant that there was limited involvement by general practices and no consent/follow-up being undertaken with children, so there was, for example, no participant information sheet for them to advise on. Due to these issues, the children's involvement in the PLEASANT trial can be classified as 'consultation' using Fleming and Hudson's model of involvement, rather than collaboration, or young person-led. The research team took on board the advice received by the children during the development of the trial, so we do not believe that we involved the children tokenistically - although we acknowledge that we might have involved the children more by asking them to design their own logo for the study, rather than selecting one from a range of logos already designed by the research team.

The ethics of involving children and young people in research have been carefully considered by previous authors. It can be argued that the range of these ethical issues differ depending on whether the children are involved as co-researchers or as advisors. McLaughlin (2007) considers that the main ethical issues when involving children as co-researchers include: obtaining ethical approval, valuing contributions, informed consent, confidentiality, authorship and ending the research. The research team did not have to face the full extent of these ethical issues due to the children's involvement being limited to advising on the design of the research, rather than being actively involved in its conduct. Despite this, the team did take the ethics of the children's involvement very seriously. Although, as per existing best practice guidance, (INVOLVE and National Research Ethics Service, 2009), we did not seek formal consent from the children and their parents ahead of either consultation event, we were mindful of the duty of care we had towards the children in particular, and took care to ensure the children both felt safe and enjoyed the experience. For example, at the first consultation event, we gave the children the option of having a separate discussion to their parents, or having a discussion which included their parents: all the children present were happy to have a separate discussion to their parents. In case any child got upset in the discussion, a researcher was present in the room in order to escort the child back to his/her parent.

We conducted two separate consultation events during the development of the PLEASANT trial, separated by fairly long intervals of time. The timing of each event was quite deliberate, as each consultation event served a distinct purpose. The first event (pre-grant submission) was to investigate whether the proposed trial had value to its main 
beneficiaries, and to invite comment on key aspects of the trial - which, in the case of the PLEASANT trial, centred around issues relating to the content and the recipient of the intervention. The second event (post-award, pre-commencement) was designed to update attendees of the first event that the grant was successful, to invite further comment on the content and timing of the intervention, to obtain input into the lay summary of the ethics submission, and to invite parents onto the TSC.

The team conducted these consultation events with small numbers of parents and children. The small number of participants was not a random sample of the population, and might not therefore be representative of the opinions that would be reported by the wider population of parents and children with asthma. INVOLVE warns against trying to seek some form of statistical representation when undertaking PPI activities; they talk about the value of seeking valid perspectives rather than representativeness (Hanley et al., 2003). We feel that valid PPI perspectives were obtained during the planning of the study, but would have sought such valid perspectives from a wider group of parents and children if time and resources allowed. The small number of people in the consultations is a reflection on: the difficulties in recruiting people to take part in PPI activities using the recruitment strategies described, the limited time-frames in which to conduct and usefully apply the findings, and the small sums of funding that are available in the UK to fund PPI activities during the grant development and preaward stages of the research cycle (Boote et al., 2013). The team acknowledges that, due to the recruitment methods used, the children in the first consultation event may have known the facilitators (H.E. and W.H.S.), due to their dual roles as clinicians and members of the research team. If there was more time to conduct the PPI before the grant application was submitted, the research team would have used other methods of recruitment, we would have held more consultation events with a wider group of children and parents, and we would have relied less on 'convenience sampling' methods. For example, the research team would have advertised the involvement opportunity in local GP surgeries and in schools, and on the People in Research website (People in Research, 2015), and would have contacted existing and relevant children's and young people's advisory groups.
Each consultation event was run as a focus group discussion. Focus groups were considered an appropriate and convenient method of information gathering during the grant development process, but the potential influence of the group dynamic, including the role of the facilitators, on the discussion should be recognised, although both facilitators took great care in ensuring that all those taking part were able to participate. Despite knowledge of the role and background of the facilitators (an academic GP and a consultant paediatrician in the first consultation event and a medical statistician at the second), the team was reassured that the parents and children were able to offer a critique of its proposals and offer some alternative ideas. Ideally, we had hoped that the same children and parents who attended the first consultation event could have attended the second. However, this proved not possible in practice and the research team had to invite new parents and children to attend the second consultation. While this had the advantage of introducing fresh perspectives, it meant that there was a change to the group dynamic, and it meant that the research team had to spend some time explaining the rationale about the trial to the new children and parents. There was concern that this exposition might have been irritating to the parents and children who attended the first consultation; however, it was considered to be a useful reorientation to the study, ahead of the discussion that followed.

The PLEASANT trial is due to be completed in November 2015. During the writing-up stage of the study, a further PPI consultation event is planned, in which the research team will seek guidance from children and their parents about how the findings can best be presented to a lay audience.

\section{Conclusion}

The value of involving patients and the public in the design and conduct of research is now widely recognised, and is health research policy in the UK and internationally. This paper has described the involvement of parents and children with asthma in the development of a major publicly funded trial that has recently taken place in the UK. Our work contributes to the small but growing number of examples of PPI in trial design and conduct and adds to the growing literature on the involvement 
of children and young people in health research Researchers wishing to actively involve children in the design of future trials may wish to draw on some of the techniques discussed in this paper. We described two consultation events in this paper: pre-grant submission and post-award, pre-commencement. We recommend that researchers consider holding such post-award, pre-commencement PPI consultation events, as they provide a useful means of providing feedback to lay people on how their input has contributed to successful grant capture.

\section{Acknowledgements}

The authors are grateful to the parents and children who took part in the two consultation events to design aspects of the PLEASANT trial.

\section{Financial Support and Disclaimer}

The first consultation event described in this paper was supported by the Public Involvement in Grant Applications Development Fund of the NIHR Research Design Service Yorkshire and Humber. Information about this award scheme can be found at: http://www.rds-yh.nihr.ac.uk/ppi/funding-award/. The report to the Research Design Service on how the funding was used can be viewed at: http://www. rds-yh.nihr.ac.uk/ppi/funding-award/success-stories/. The PLEASANT trial is funded by NIHR Health Technology Assessment (grant number HTA-11/ 01/10). The views expressed are those of the author(s) and not necessarily those of the NHS, the NIHR or the Department of Health.

\section{Conflicts of Interest}

None.

\section{Ethical Standards}

This paper reports the findings of a PPI consultation process, and not the findings of a research project. The consultation process was informed by the guidance document from INVOLVE and the National Research Ethics Service. This guidance states that, 'The active involvement of patients or members of the public does not generally raise any ethical concerns for the people who are actively involved, even when those people are recruited for this role via the NHS. This is because they are not acting in the same way as research participants. They are acting as

Primary Health Care Research \& Development 2016; 17: 536-548 specialist advisers, providing valuable knowledge and expertise based on their experience of a health condition or public health concern. Therefore ethical approval is not needed for the active involvement element of the research, (even when people are recruited via the NHS), where people are involved in planning or advising on research, eg, helping to develop a protocol, questionnaire or information sheet, member of advisory group, or co-applicant'. The parents participating in the consultation process were not therefore required to formally consent either themselves or their children.

\section{References}

Alderson, P. 2001: Research by children. International Journal of Social Research Methodology 4, 139-53.

Barber, R., Beresford, P., Boote, J., Cooper, C. and Faulkner, A. 2011: Evaluating the impact of public involvement on research: a prospective case study. International Journal of Consumer Studies 35, 509-615.

Boote, J., Baird, W. and Sutton, A. 2011: Public involvement in the design and conduct of clinical trials: a review. The International Journal of Interdisciplinary Social Sciences 5, 91-111.

Boote, J., Wong, R. and Booth, A. 2015a: "Talking the talk or walking the walk?" A bibliometric review of the literature on public involvement in health research published between 1995 and 2009. Health Expectations 18, 44-57.

Boote, J., Jones, Z., McKevitt, C., Wallace-Watson, C. and Rogers, H. 2015b: Public involvement in, and engagement with, studies adopted onto the NIHR Stroke Research Network: questionnaire survey. International Journal of Stroke 10, E6-E7.

Boote, J., Twiddy, M., Baird, W., Birks, Y., Clarke, C. and Beever, D. 2013: Supporting public involvement in research design and grant development: a case study of a public involvement award scheme managed by a National Institute for Health Research (NIHR) Research Design Service (RDS). Health Expectations. Early View (online version). doi:10.1111/hex.12130.

Brett, J., Staniszewska, S., Mockford, C., Seers, K., HerronMarx, S. and Bayliss, H. 2010: The PIRICOM study: $a$ systematic review of the conceptualisation, measurement, impact and outcomes of patients and public involvement in health and social care research. London: UK Clinical Research Collaboration Retrieved 20 April 2015 from http://www.ukcrc.org/wp-content/uploads/2014/03/Piricom+ Review+Final+2010.pdf.

Brownlie, J., Anderson, S., Ormston, R. 2006: Children as researchers. Scottish Executive Social Research and SEED Sponsored Research. Available at http://www.gov. scot/Resource/Doc/925/0080040.pdf 
Canadian Institutes of Health Research. 2010: Citizen engagement framework. Retrieved 20 April 2015 from http://www. cihr-irsc.gc.ca/e/41753.html.

Clavering, E.K. and McLaughlin, J. 2010: Children's participation in health research: from objects to agents? Child Care Health and Development 36, 603-11.

Consumers in NHS Research. 2000: Involving consumers in randomised controlled trials. Report of a seminar organised by Consumers in NHS Research and the Medical Research Council Clinical Trials Unit.

Couzos, S., Lea, T., Murray, R. and Culbong, M. 2005: 'We are not just participants-we are in charge': the $\mathrm{NACCHO}$ ear trial and the process for Aboriginal community-controlled health research. Ethnicity and Health 10, 91-111.

Department of Health. 2005: Research governance framework for health and social care, second edition. London: Department of Health.

Edwards, V., Wyatt, K., Logan, S. and Britten, N. 2011: Consulting parents about the design of a randomized controlled trial of osteopathy for children with cerebral palsy. Health Expectations 14 (4), 429-38.

Fleming, J. and Hudson, N. 2009: Young people and research: participation in practice. In Wood, J. and Hine, J., editors Work with young people: theory and policy for practice. London: Sage, 114-26.

Gorin, S., Hooper, C., Dyson, C. and Cabral, C. 2008: Ethical challenges in conducting research with hard to reach families. Child Abuse Review 17, 275-87.

Hanley, B., Truesdale, A., King, A., Elbourne, D. and Chalmers, I. 2001: Involving consumers in designing, conducting, and interpreting randomised controlled trials: questionnaire survey. British Medical Journal 322, 519-23.

Hanley, B., Bradburn, J., Barnes, M., Gorin, S., Evans, C., Goodare, H., Kelson, M., Kent, A., Oliver, S., Thomas, S. and Wallcraft, J. 2003. Involving the public in NHS, public health and social care research: briefing notes for researchers, second edition. Eastleigh: INVOLVE.

Hart, R. 1992: Children's participation from Tokenism to Citizenship. Florence: Innocenti Research Centre.

Horspool, M., Julious, S.A., Boote, J., Bradburn, M.J., Cooper, C.L., Davis, S., Elphick, H., Norman, P., Smithson, W.H. and van Staa, T. 2013: Preventing and lessening exacerbations of asthma in school-age children associated with a new term (PLEASANT): study protocol for a cluster randomised control trial. Trials 14, 297.

INVOLVE. 2015: What is public involvement in research? Retrieved 20 April 2015 from http://www.invo.org.uk/findout-more/what-is-public-involvement-in-research-2/.

INVOLVE. 2015: Involving children and young people. Retrieved 28 August 2015 from http://www.invo.org.uk/ find-out-more/involving-children-and-young-people/.

INVOLVE and National Research Ethics Service: 2009: Patient and public involvement in research and research ethics committee review, Retrieved 28 April 2015 from http://www.
invo.org.uk/wp-content/uploads/2011/12/INVOLVENRESfinal Statement310309.pdf.

Julious, S.A., Jiwa, M. and Osman, L. 2007: Hospital asthma admissions in school age asthmatics associated with the return back to school. Public Health 121, 482-84.

Julious, S.A., Campbell, M.J., Bianchi, S.M. and MurrayThomas, T. 2011: Seasonality of medical contacts in school-aged children with asthma: association with school holidays. Public Health 125, 769-76.

Kellett, M. 2005: Children as active researchers: A new research paradigm for the 21st century? ESRC, UK. Retrieved 28 August 2015 from http://oro.open.ac.uk/7539/1/.

Kellett, M. 2009: Children and young people's participation. In H. Montogomery and M. Kellett, editors Children and young people's worlds. Bristol: Policy Press, 43-60.

Kirby, P. 2004: A guide to actively involving young people in research: for researchers, research commissioners, and managers. Eastleigh: INVOLVE.

Koniotou, M., Evans, B., Chatters, R., Fothergill, R., Garnsworthy, C., Gaze, S., Halter, M., Mason, S., Peconi, M., Porter, A., Siriwardena, A., Toghill, A. and Snooks, H. 2015: Involving older people in a multi-centre randomised trial of a complex intervention in pre-hospital emergency care: implementation of a collaborative model. Trials 16, 298.

Littlewood, C., Ashton, J., Scott, E., Mawson, S., May, S. and Walters, S. 2013: Developing the SELF study: focus group with patients and the public. International Journal of Therapy and Rehabilitation 20, 200-6.

McCarry, M. 2012: Who benefits? A critical reflection of children and young people's participation in sensitive research. International Journal of Social Research Methodology 15, 55-68.

McCarry, M. 2005: Conducting social research with young people: ethical considerations. In T. Skinner, M. Hester and E. Malos, editors Researching women and violence: creating evidence for change. Devon: Willan Publishing, 87-104.

McLaughlin, H. 2005: Young service users as co-researchers: Methodological problems and possibilities. Qualitative Social Work 4, 211-28.

McLaughlin, H. 2006: Involving young service users as coresearchers: possibilities, benefits and costs. British Journal of Social Work 36, 1395-410.

McLaughlin, H. 2007: Ethical issues in the involvement of young service users in research. Ethics and Social Welfare 1, 176-93.

Morrow, V. and Richards, M. 1996: The ethics of social research with children: an overview. Children and Society 10, 90-105.

National Children's Bureau: 2010: Young People in Research: How to involve us. Guidance for researchers from the PEAR young people's public health group. Retrieved 28 August from http://www.participationworks.org.uk/files/ webfm/files/resources/k-items/ncb/Pear\%20Leaflet_final_ lores.pdf. 
National Health \& Medical Research Council and Consumers' Health Forum of Australia. 2002: Statement on consumer and community participation in health and medical research. Retrieved 20 April 2015 from www.nhmrc.gov. au/guidelines-publications/r22-r23-r33-r34.

National Institute for Health Research. 2015: Patient and public involvement. Retrieved 20 April 2015 from http://www.nets. nihr.ac.uk/ppi.

Oliver, K., Rees, R., Brady, L.-M., Kavanagh, J., Oliver, S. and Thomas, J. 2015: Broadening public participation in systematic reviews: a case example involving young people in two configurative reviews. Research Synthesis Methods 6, 206-17.

Partridge, N. and Scadding, J. 2004: The James Lind Alliance: patients and clinicians should jointly identify their priorities for clinical trials. The Lancet 364, 923-1924.

Patient Protection and Affordable Care Act. 2010: Public Law, 111-148.

People in Research. 2015: Retrieved 28 August 2015 from http://www.peopleinresearch.org/.

Shippee, N., Garces, J.P.D., Prutsky, G.L., Lopez, G.J., Wang, Z., Elraiyah, T.A., Nabhan, M., Brito, J.P., Boehmer, K., Hasan, R., Firwana., B., Erwin, P.J., Montori, V.M. and Murad, M.H. 2013: Patient and service user engagement in research: a systematic review and synthesized framework. Health Expectations 18, 1151-66.

Staley, K. 2009. Exploring impact: public involvement in NHS, public health and social care research. Eastleigh: INVOLVE Retrieved 20 April 2015 from http://www.invo.org.uk/ posttypepublication/exploring-impact-public-involvement-innhs-public-health-and-social-care-research/.

Staniszewska, S., Herron-Marx, S. and Mockford, C. 2008: Measuring the impact of patient and public involvement: the need for an evidence base. International Journal for Quality in Health Care 20, 373-74.

Thomas, N. and O'Kane, C. 1998: The ethics of participatory research with children. Children and Society 12, 336-48.

Uprichard, E. 2010: Questioning research with children: discrepancy between theory and practice? Children \& Society 24, 3-13.

Vale, C., Thompson, L., Murphy, C., Forcat, S. and Hanley, B. 2012: Involvement of consumers in studies run by the Medical Research Council Clinical Trials Unit: results of a survey. Trials 13, 9 .

Williams, T., van Staa, T., Puri, S. and Eaton, S. 2012: Recent advances in utility and use of the General Practice Research Database as an example of a UK primary care data resource. Therapeutic Advances in Drug Safety 3, 88-99. 